\title{
Vascularização foliar e a identificação de espécies de Eugenia $L$. (Myrtaceae) da bacia hidrográfica do Rio Tibagi, PR
}

\author{
CRISTIANO M.V. CARDOSO ${ }^{1}$ e MARIA DAS GRAÇAS SAJO ${ }^{2,3}$
}

(recebido: 3 de abril de 2002; aceito: 23 de outubro de 2003)

\begin{abstract}
Vasculature and identification of Eugenia (Myrtaceae) from the bank of Tibagi river, State of Paraná). With the objective of recognizing vegetative helpfull characteristics in the Myrtaceae identification, we studied the leaf anatomy of 17 species of Eugenia, from the bank of Tibagi river, State of Paraná. Using leaf blade venation and, the pattern of the petiole vascular bundle sheaths we separated the species in three different groups. The camptodromous-brochidodromous venation pattern occur in nine species, the acrodromous pattern in four species, and a mixed pattern in four species. Depending on the species, the petiole vascular bundle sheaths can be of parenchymatous, sclerenchymatous or mixed nature. A dicotomic identification key was elaborated with these vegetative characters showing that they can surely aid in the Eugenia species identification.
\end{abstract}

Key words - Eugenia, leaf venation, Myrtaceae

RESUMO - (Vascularização foliar e identificação das espécies de Eugenia (Myrtaceae) da bacia hidrográfica do Rio Tibagi, PR). Com o objetivo de reconhecer caracteres vegetativos que auxiliem na identificação de Myrtaceae, foram estudadas as folhas de 17 espécies de Eugenia, presentes da bacia do Rio Tibagi, PR. Analisando os padrões de nervação das lâminas e as características da bainha perivascular, na região do pecíolo, foi possível separar essas espécies em três grupos distintos. O padrão camptódromo-broquidódromo ocorre em nove espécies; o acródromo em quatro espécies e, nas quatro restantes, observa-se um padrão misto. A bainha perivascular do pecíolo pode ser de natureza parenquimática, esclerenquimática ou mista. Elaborou-se uma chave de identificação usando esses caracteres vegetativos, demonstrando que eles podem, seguramente, auxiliar na identificação das espécies de Eugenia.

Palavras-chave - Eugenia, Myrtaceae, nervação foliar

\section{Introdução}

Em todos os ecossistemas brasileiros, as Myrtaceae se destacam como uma das famílias mais importantes e diversificadas (Mori et al. 1983, Fabris \& Cesar 1996), sendo o gênero Eugenia L. um dos maiores, com cerca de 500 espécies. Apesar dessa importância, os representantes da família tem sido pouco estudados sob o ponto de vista morfo-anatômico, destacando-se apenas os trabalhos sobre anatomia foliar de Johnson (1980), com o gênero Leptospermum, e de Keating (1984), que discutiu as relações de alguns gêneros de Myrtaceae, dentro da ordem Myrtales.

Com relação a Eugenia, citam-se os estudos de Khatijah et al. (1992), que demonstraram o potencial da anatomia foliar na identificação de material estéril, os de Du Plessis \& Van Wik (1982), que estudaram

\footnotetext{
1. Parte da dissertação de mestrado de C.M.V. Cardoso, na Universidade Estadual Paulista.

2. Universidade Estadual Paulista, Instituto de Biociências, Departamento de Botânica, Caixa Postal 199, 13506-900 Rio Claro, SP, Brasil.

3. Autor para correspondência: cmviana@rc.unesp.br
}

várias características morfológicas foliares e sua aplicabilidade na identificação de seis espécies e os de Klucking (1988), que descreveu os padrões de nervação foliar para 128 espécies. A vascularização foliar de Eugenia foi utilizada como subsídio para identificação de espécies por Fontenelle et al. (1994) e por Costa et al. (1995).

Levando-se em conta a representatividade do gênero Eugenia, nas formações vegetais brasileiras, e as dificuldades encontradas para a delimitação taxonômica de seus representantes, no presente trabalho são estudadas as folhas, de 17 espécies desse gênero presentes na bacia do Rio Tibagi, PR, com os seguintes objetivos: descrever os padrões de nervação encontrados, reconhecer os tipos de organização vascular no pecíolo e indicar caracteres úteis na identificação desses táxons.

\section{Material e métodos}

A bacia do Rio Tibagi, localizada na porção centro-leste do Paraná (figura 1), é uma das maiores no Estado (Balhana et al. 1969, Maack 1968) e apresenta uma fisionomia vegetal variada composta, predominantemente, por campos limpos 


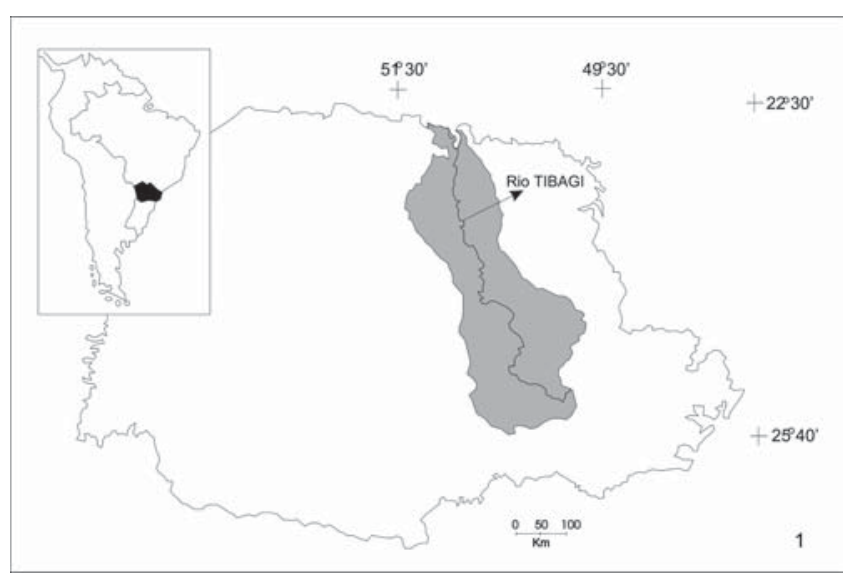

Figura 1. Localização da bacia hidrográfica do Rio Tibagi (ロ) no Estado do Paraná (ם).

Figure 1. Localization of the Tibagi River bank ( $\square$ ) in Parana State (ם).

entremeados por capões de matas esparsos e por matas ciliares, ao longo dos rios. Ocorrem também alguns remanescentes de cerrado, além de áreas de floresta pluvial subtropical, onde crescem árvores de grande porte, epífitas, lianas diversas e palmeiras como Euterpe edulis Mart (Maack, 1968). As espécies estudadas crescem em formações vegetais arbóreas (cerrado, matas de galeria e floresta pluvial subtropical) e as folhas foram retiradas das seguintes exsicatas, do acervo do Herbário da Universidade Estadual de Londrina (FUEL): Eugenia arenosa Mattos (FUEL18875, 16023, 14975); E. blastantha (O. Berg) D. Legrand (FUEL 18484, 2378, 14970); E. burkartiana (D. Legrand) D. Legrand (FUEL 17042, 17800, 18928); E. florida DC. (FUEL 17004, 21293, 18744); E. hamiltonii (Mattos) Mattos FUEL (16050, 18922, 18980); E. handroana D. Legrand (FUEL 18505, 18506, 17191); E. hiemalis Cambess. (FUEL 18471, 18474, 9369); E. involucrata DC. (FUEl 17732, 18754, 18767); E. moraviana O. Berg (FUEL 16079, 17044, 2382); E. neoverrucosa Sobral (FUEL 18480, 18780, 15008); E. pitanga (O. Berg) Kiaersk. (FUEL 19013, 16025, 16021); E. punicifolia (Kunth) DC.(FUEL 18497, 18916, 18715); E. pyriformis Cambess. (FUEL 16028, 19492, 17036); E. ramboi D. Legrand (FUEL 12229, 10967, 17091); E. speciosa Cambess. (FUEL 18810, 19024, 19036); E. uniflora L. (FUEL 19008, 18970); E. uruguayensis Cambess. (FUEL 16006, 18991, 14982).

Para o estudo de nervação, folhas perfeitamente desenvolvidas foram diafanizadas, segundo Shobe \& Lersten apud Kraus \& Arduin (1997), e montadas entre placas de vidro. A rede menor de nervuras foi observada e registrada a partir de fragmentos, do terço mediano de folhas diafanizadas, montados em lâminas permanentes. A descrição e classificação dos padrões de nervação seguiu os tipos básicos definidos por Hickey (1974). Quando uma mesma folha mostrou uma combinação de padrões definidos, o padrão foi chamado misto e a folha descrita por partes. O sistema vascular do pecíolo foi estudado em folhas totalmente expandidas, preferencialmente do terceiro ou quarto nós, analisando-se cinco amostras de cada espécie. Para tanto foram confeccionados, à mão livre, cortes transversais na região apical pois, segundo Howard (1979) e Costa et al. (1995), é a porção mais estável e, portanto, mais segura para se analisar a configuração do sistema vascular. Os cortes foram clarificados com hipoclorito de sódio $10 \%$ por $1-5$ minutos, lavados em água destilada, submetidos à dupla coloração com safrablau $(5 \mathrm{~mL}$ de solução aquosa de safranina $1 \%$ - $95 \mathrm{~mL}$ de solução aquosa de azul de Astra 1\% - duas gotas de ácido acético glacial), montados em gelatina glicerinada (Haupt apud Kraus \& Arduin 1997) e examinados ao microscópio de luz Zeiss (Axiolab). Os diagramas foram realizados em microscópio Olympus CBA, com emprego da câmara clara e projeção de escala micrométrica. O registro do padrão de nervação foi feito a partir de ampliações das folhas diafanizadas (utilizando um ampliador fotográfico Durst M601) e a rede menor de nervuras foi fotografada em fotomicroscópio Olympus BX40.

\section{Resultados e Discussão}

Vascularização foliar - Das 17 espécies de Eugenia estudadas, nove apresentam um padrão de nervação foliar que tende para o camptódromo-broquidódromo (figuras 2, 3; tabela 1), onde as nervuras secundárias se anastomosam, desde a base da folha, e formam uma série de arcos próximos ao bordo. Dependendo do ângulo de fechamento, os arcos ou laços broquidódromos podem ser mais ou menos proeminentes. Em geral, são mais proeminentes na base da folha, onde freqüentemente formam laços de ordem superior.

O padrão acródromo (figuras 4, 5) ocorre em quatro espécies (tabela 1) e, nesse caso, as folhas apresentam duas nervuras secundárias basais (geralmente o primeiro par), que se dirigem para o ápice em arcos convergentes. Ao longo delas conectam-se outras nervuras, geralmente, de mesma ordem (originadas da nervura mediana), formando o sistema típico do padrão.

Considerou-se padrão broquidódromo quando os ângulos de fechamento (no ponto de anastomose das nervuras secundárias) são na maioria retos, ou próximos dele, e formam arcos evidentes; no padrão acródromo, os ângulos de fechamento são mais abertos (obtusos) e configuram "arcos" muito tênues, que originam a nervura marginal comum das Myrtaceae.

Para as folhas das demais espécies (tabela 1), observou-se um padrão misto acródromobroquidódromo (figuras 6,7 ). Nesse padrão, observa-se de um a três pares de nervuras secundárias laterais (de 

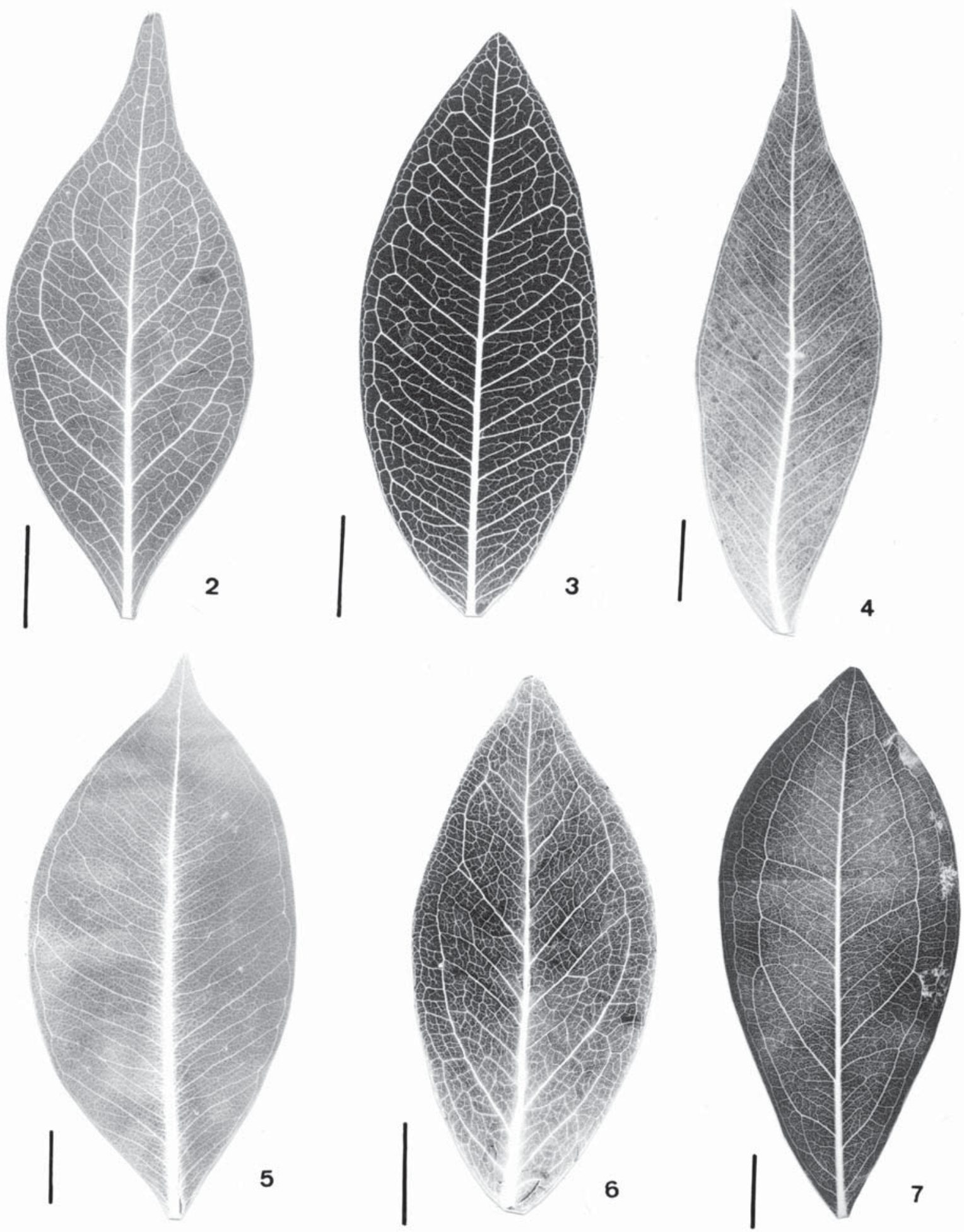

Figuras 2-7. Padrões de nervação observados em folhas de Eugenia. 2-3. Padrão camptódromo-broquidódromo. 2. E. uniflora. 3. E pyriformis. 4-5. Padrão acródromo. 4. E. uruguayensis. 5. E. blastantha. 6-7. Padrão acródromo-broquidódromo. 6. E. pitanga. 7. E. burkartiana. Barras $=1 \mathrm{~cm}$.

Figures 2-7. Venation patterns in Eugenia leaves. 2-3. Camptodromous-brochidodromous pattern. 2. E. uniflora. 3. E. pyriformis. 4-5. Acrodromous pattern. 4. E. uruguayensis. 5. E. blastantha. 6-7. Acrodromous-brochidodromous pattern. 6. E. pitanga. 7. E. burkartiana. Bars $=1 \mathrm{~cm}$. 
Tabela 1. Nervação foliar em espécies do gênero Eugenia (Myrtaceae) da bacia do Rio Tibagi (Paraná, Brasil).

Table 1. Leaf venation patterns in Eugenia (Myrtaceae) species from the bank of the Tibagi River (State of Paraná, Brazil).

\begin{tabular}{|c|c|c|c|c|c|c|}
\hline \multirow[b]{2}{*}{ Espécies } & \multicolumn{3}{|c|}{ Padrão de nervação secundário } & \multicolumn{3}{|c|}{ Nervação última marginal } \\
\hline & $\begin{array}{l}\text { Camptódromo- } \\
\text { broquidódromo }\end{array}$ & Acródromo & $\begin{array}{l}\text { Acródromo- } \\
\text { broquidódromo }\end{array}$ & Fimbrial & Imcompleta & Arcos \\
\hline E. arenosa & $\mathrm{X}$ & & & & & $\mathrm{X}$ \\
\hline E. blastantha & & $\mathrm{X}$ & & & $\mathrm{X}$ & \\
\hline E. burkartiana & & & $\mathrm{X}$ & $\mathrm{X}$ & & \\
\hline E. florida & & & $\mathrm{X}$ & $\mathrm{X}$ & & \\
\hline E.hamiltonii & $\mathrm{X}$ & & & $\mathrm{X}$ & & \\
\hline E. handroana & $\mathrm{X}$ & & & & $\mathrm{X}$ & \\
\hline E. hiemalis & $\mathrm{X}$ & & & $\mathrm{X}$ & & \\
\hline E. involucrata & & $\mathrm{X}$ & & & $\mathrm{X}$ & \\
\hline E. moraviana & & & $\mathrm{X}$ & $\mathrm{X}$ & & \\
\hline E. neoverrucosa & $\mathrm{X}$ & & & & $\mathrm{X}$ & \\
\hline E. pitanga & & & $\mathrm{X}$ & & & $\mathrm{X}$ \\
\hline E. punicifolia & & $\mathrm{X}$ & & $\mathrm{X}$ & & \\
\hline E. pyriformis & $\mathrm{X}$ & & & & $\mathrm{X}$ & \\
\hline E. ramboi & $\mathrm{X}$ & & & $\mathrm{X}$ & & \\
\hline E. speciosa & $\mathrm{X}$ & & & & & $X$ \\
\hline E. uniflora & $\mathrm{X}$ & & & & & $X$ \\
\hline E. uruguayensis & & $\mathrm{X}$ & & & & $\mathrm{X}$ \\
\hline
\end{tabular}

origem basal ou supra basal), que tendem ao padrão acródromo até o terço mediano da folha, quando se unem a outras nervuras, também secundárias, formando arcos broquidódromos. O par interno de nervuras acródromas, geralmente, tem origem supra basal e se prolonga até o ápice da lâmina; já o par externo, de origem basal, corre junto ou muito próximo à margem do orgão (figuras 6,7 ).

Embora Klucking (1988) considere o padrão de nervação acródromo como o predominante em Myrtaceae (inclusive em Eugenia), o padrão mais freqüente, observado no presente estudo, foi o camptódromo-broquidódromo, seguido pelo tipo misto acródromo-broquidódromo e, finalmente, pelo tipo acródromo (tabela 1). Esses resultados coincidem com os obtidos por Costa et al. (1995), que descreveram o padrão camptódromo-broquidódromo para seis das onze espécies de Eugenia, ocorrentes na restinga de Maricá - RJ.

Os ângulos de divergência, entre as nervuras secundárias e mediana, variam entre $45^{\circ}$ e $60^{\circ}$ e são maiores no terço superior de todas as folhas estudadas, sendo mais marcante nas espécies com padrão misto de nervação (figuras 6,7 ).

Conforme observado na tabela 1 , ocorre um predomínio do padrão fimbriado de nervação última marginal, que se caracteriza pela fusão das nervuras próximas ao bordo, originando uma nervura contínua (nervura fimbrial), que corre junto a margem (figura 8). Em E. blastantha, E. involucrata, E. handroana, E. neoverrucosa e E. pyriformis, a nervação última marginal é incompleta (tabela 1) pois, em geral, as nervuras terminam livres próximo à margem (figura 9). Nas demais espécies, a nervação última marginal é constituída por uma série de arcos de onde podem se originar nervuras mais delgadas (figura 10).

Como observado por Klucking (1988) e Costa et al. (1995), para outras Myrtaceae, as nervuras terciárias e de ordem superior determinam aréolas incompletas, de formato irregular e distribuídas ao acaso (figura 11). No presente trabalho, somente E. arenosa e E. hamiltonii apresentam aréolas completas, com a forma variando de quadrangular a pentagonal (figura 12). Na mesma folha as terminações vasculares, representadas por traqueídes e, geralmente, por esclereídes (figura 13), podem ser ramificadas (figura 13) ou não (figura 14).

Sistema vascular no pecíolo - Segundo Howard (1979), a estrutura anatômica do pecíolo auxilia no reconhecimento de determinados táxons, sendo que a observação de sua secção distal pode, em muitos casos, ser suficiente, para identificar a família e, em alguns casos, até o gênero de determinadas plantas. 


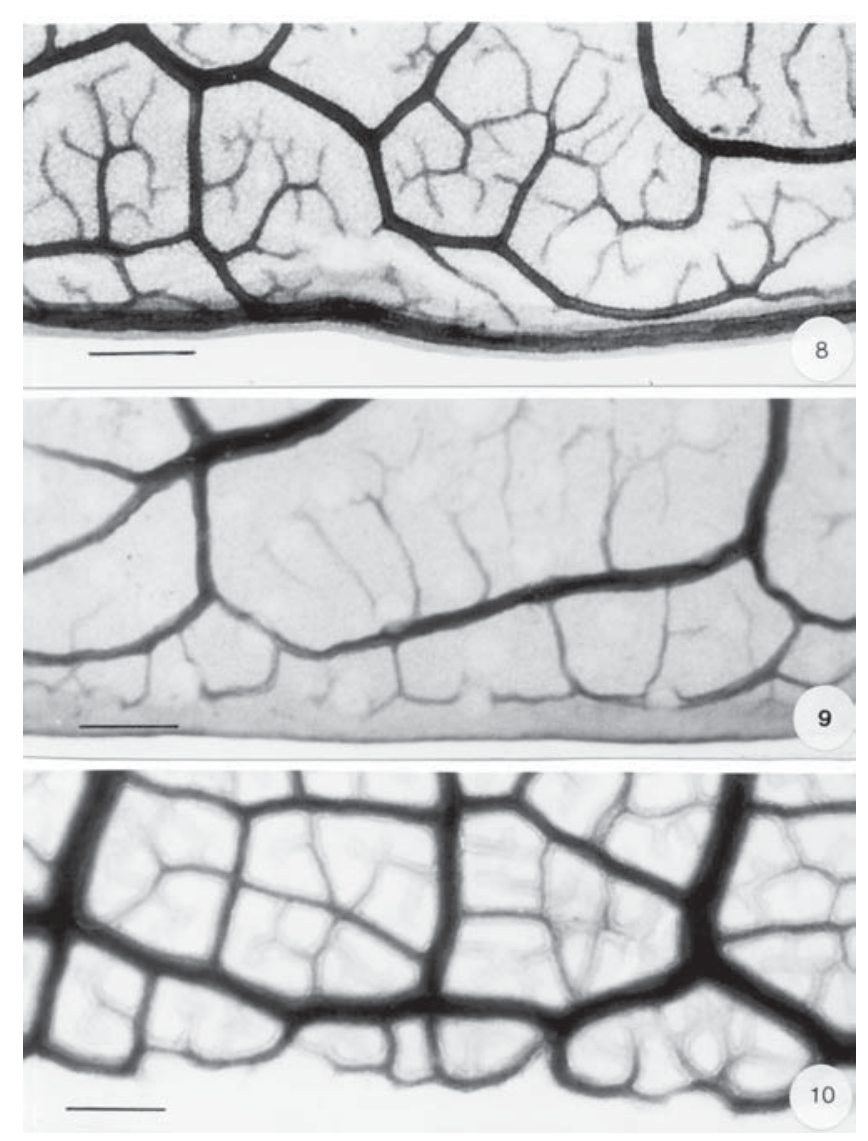

Figuras 8-10. Nervação última marginal observada em folhas de Eugenia. 8. E. ramboi, fimbriada. 9. E. blastantha, incompleta. 10. E. arenosa, em arcos. Barras $=0,25 \mathrm{~mm}$.

Figures 8-10. Marginal ultimate venation in Eugenia leaves. 8. E. ramboi, fimbriated. 9. E. blastantha, incomplete. 10. E. arenosa, looped. Bars $=0.25 \mathrm{~mm}$.

No presente estudo, a análise de cortes transversais da região apical dos pecíolos permitiu identificar três grupos de espécies, de acordo com a configuração do arco vascular (tabela 2), bicolateral (floema nas duas faces), que é envolvido por uma única bainha. Esse arco pode ser atenuado (figura 15), apresentar extremidades eretas (figura 16), ou dirigidas para o centro (figura 17).

Solereder (1908) faz alusão à presença de uma bainha perivascular no pecíolo das Myrtaceae que, segundo Howard (1979), é formada por fibras e apresenta espessura variável, de acordo com a espécie considerada. Khatijah et al. (1992) e Costa et al. (1995) utilizaram a natureza das células dessa bainha como caráter taxonômico, para delimitar espécies de Eugenia. No presente trabalho, observou-se que a bainha perivascular pode ser constituída por células parenquimáticas (figura 15), por células esclerificadas (figura 17) ou apresentar natureza mista (figura 16), dependendo da espécie considerada (tabela 2).

Idioblastos, portadores de drusas e de cristais prismáticos ou romboédricos, estão presentes no clorênquima do pecíolo de todas as espécies, onde também se observam cavidades secretoras e compostos de natureza fenólica no interior das células.

O padrão de nervação secundário, o tipo de nervação última marginal e a composição da bainha perivascular no pecíolo, variam entre as espécies estudadas (tabelas 1-2). Combinando-se essas características, foi possível elaborar uma chave de identificação para as espécies de Eugenia da bacia hidrográfica do Rio Tibagi.
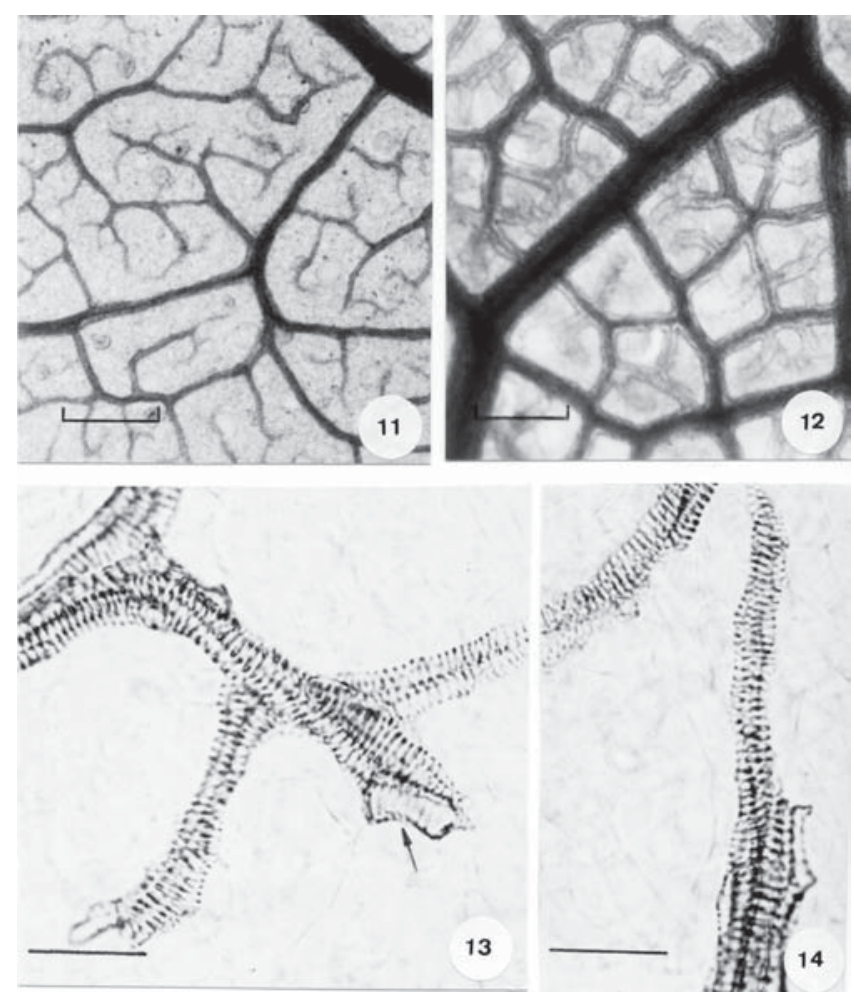

Figuras 11-14. Areolação e terminações vasculares observadas em folhas de Eugenia. 11. E. hiemalis. Aréolas incompletas. 12. E. speciosa. Aréolas completas. 13. E. speciosa. Terminação vascular ramificada com esclereídes (seta). 14. E. handroana. Terminação vascular não ramificada. Barras $=0,25 \mathrm{~mm}(11,12) ; 0,1 \mathrm{~mm}(13,14)$.

Figures 11-14. Areolation and vascular terminations in Eugenia leaves. 11. E. hiemalis. Incomplete areoles. 12. E. speciosa. Complete areoles. 13. E. speciosa. Vascular branched termination with sclereids (arrow). 14. E. handroana. Vascular termination not branched. Bars $=0.25 \mathrm{~mm}(11,12)$; $0.1 \mathrm{~mm}(13,14)$. 
Tabela 2. Configuração do sistema vascular no pecíolo em espécies do gênero Eugenia (Myrtaceae) da bacia do Rio Tibagi (Paraná, Brasil).

Table 2. Vascular system configuration of petiole in Eugenia (Myrtaceae) species from the bank of the Tibagi River (State of Paraná, Brazil).

\begin{tabular}{|c|c|c|c|c|c|c|}
\hline \multirow[b]{2}{*}{ Espécies } & \multicolumn{3}{|c|}{ Bainha perivascular } & \multicolumn{3}{|c|}{ Morfologia do feixe vascular } \\
\hline & Parenquimática & Esclerenquimática & Mista & Arco atenuado & $\begin{array}{c}\text { Arco com } \\
\text { extremidades fletidas }\end{array}$ & $\begin{array}{c}\text { Arco com } \\
\text { extremidades eretas }\end{array}$ \\
\hline E. arenosa & & $\mathrm{X}$ & & & $\mathrm{X}$ & \\
\hline E. blastantha & $\mathrm{X}$ & & & & & $\mathrm{X}$ \\
\hline E. burkartiana & & & $\mathrm{X}$ & & $\mathrm{X}$ & \\
\hline E. florida & & & $\mathrm{X}$ & & $\mathrm{X}$ & \\
\hline E. hamiltonii & & & $\mathrm{X}$ & $\mathrm{X}$ & & \\
\hline E. handroana & & & $\mathrm{X}$ & & $\mathrm{X}$ & \\
\hline E. hiemalis & & $\mathrm{X}$ & & & $X$ & \\
\hline E. involucrata & $\mathrm{X}$ & & & & & $\mathrm{X}$ \\
\hline E. moraviana & & & $\mathrm{X}$ & & & $\mathrm{X}$ \\
\hline E. neoverrucosa & & & $\mathrm{X}$ & & $\mathrm{X}$ & \\
\hline E. pitanga & & & $X$ & & $\mathrm{X}$ & \\
\hline E. punicifolia & & & $\mathrm{X}$ & & & $\mathrm{X}$ \\
\hline E.pyriformis & & & $\mathrm{X}$ & & $\mathrm{X}$ & \\
\hline E. ramboi & & & $\mathrm{X}$ & & & $\mathrm{X}$ \\
\hline E. speciosa & $\mathrm{X}$ & & & $\mathrm{X}$ & & \\
\hline E. uniflora & & & $\mathrm{X}$ & $\mathrm{X}$ & & \\
\hline E. uruguayensis & & $\mathrm{X}$ & & & & $\mathrm{X}$ \\
\hline
\end{tabular}

Chave de identificação para espécies de Eugenia da bacia hidrográfica do Rio Tibagi

1. Nervação secundária do tipo camptódromo-broquidódromo

2. Nervação última marginal formando arcos ou nervura fimbrial

3. Nervação última marginal se fusionando em uma única nervura, muito próxima ou rente ao bordo (nervura fimbrial)

4. Aréolas completas.

E. hamiltonii

4. Aréolas incompletas de formato irregular com muitas terminações vasculares livres

5. Bainha perivascular no pecíolo esclerenquimática ao nível distal

E. hiemalis

5. Bainha perivascular no pecíolo mista ao nível distal

E. ramboi

3. Nervação última marginal formando arcos

6. Aréolas completas de formato regular, quadrangular a pentagonal.

E. arenosa

6. Aréolas incompletas de formato irregular

7. Bainha perivascular no pecíolo parenquimática ao nível distal

E. speciosa

7. Bainha perivascular no pecíolo mista ao nível distal

E. uniflora

2. Nervação última marginal incompleta

8. Nervuras terciárias e de ordem superior acompanhadas por uma bainha parenquimática

E. handroana

8. Nervuras terciárias e de ordem superior sem essa característica

9. Ângulos de divergência das nervuras secundárias com a nervura mediana por volta de $45^{\circ}$

E. pyriformis

9. Ângulos de divergência das nervuras secundárias com a nervura mediana maiores que $45^{\circ}$

E. neoverrucosa

1. Nervação secundária mista (acródromo-broquidódromo) ou acródromo

10. Nervação secundária do tipo acródromo 
11. Nervação última marginal formando arcos ou nervuras fimbrial

12. Nervação última marginal se fusionando em uma única nervura, muito próxima ou rente ao bordo - nervura fimbrial

E. punicifolia

12. Nervação última marginal formando arcos E. uruguayensis

11. Nervação última marginal incompleta E. involucrata

E. blastantha

10. Nervação secundária do tipo misto, acródromo-broquidódromo

13. Nervação última marginal formando arcos

E. pitanga

13. Nervação última marginal fimbrial

14. Nervura marginal dupla, com o par interno de nervuras acródromas bastante evidente

E. burkartiana

14. Nervura marginal dupla, sem essa característica

15. Sistema vascular no pecíolo ao nível distal formando um arco atenuado ou com as extremidades ligeiramentes eretas E. moraviana

15. Sistema vascular no pecíolo ao nível distal formando arco com extremidades dirigidas para o centro

E. florida
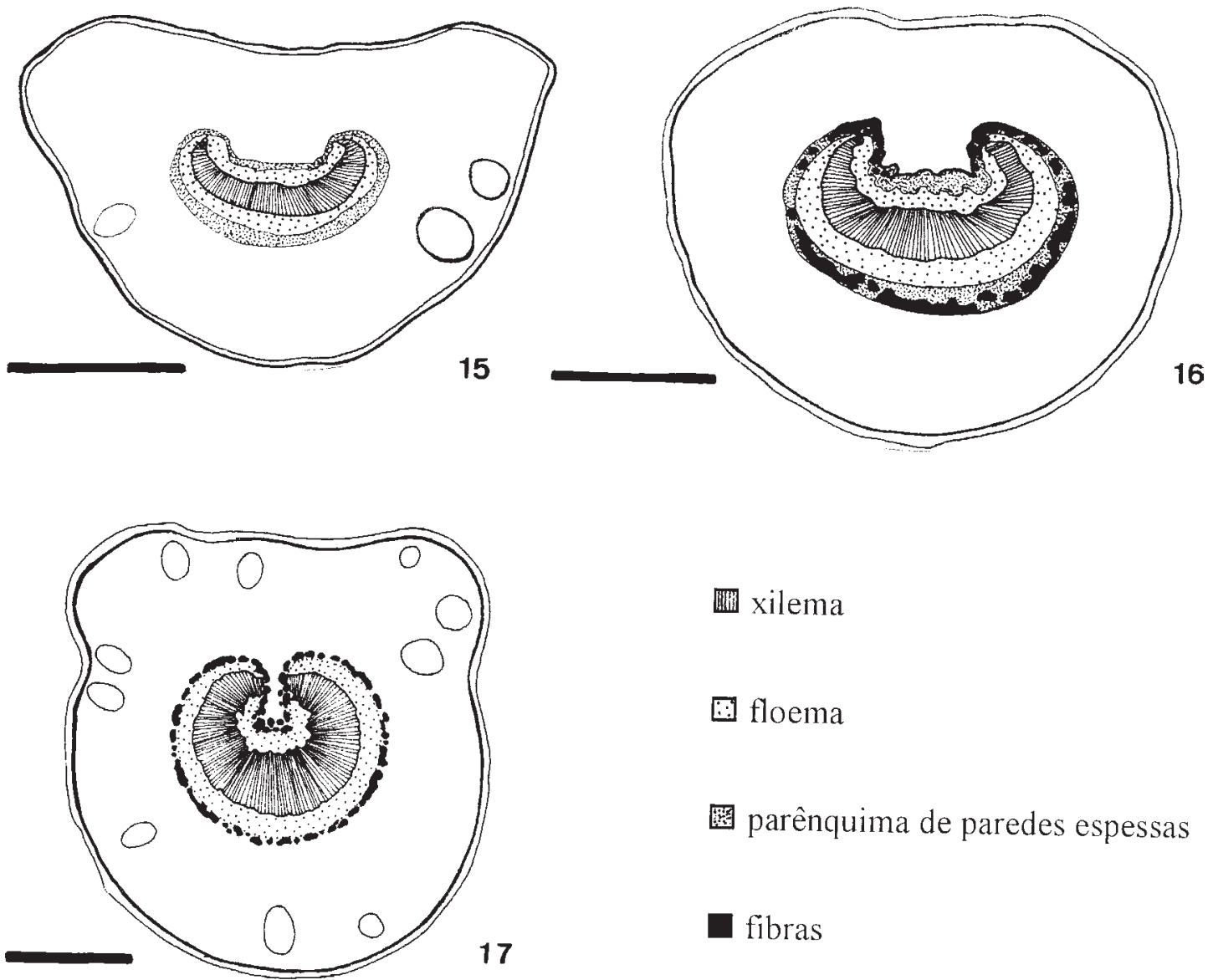

Figuras 15-17. Diagramas de cortes transversais de pecíolo de Eugenia mostrando a configuração do sistema vascular. 15. E. speciosa. Arco atenuado. 16. E. punicifolia. Arco com extremidades eretas. 17. E. hiemalis. Arco com as extremidades fletidas. Barras $=0,5 \mathrm{~mm}(15,16) ; 0,25 \mathrm{~mm}(17)$.

Figures 15-17. Diagrams of cross sections of Eugenia petiole showing the vascular system configuration. 15. E. speciosa. Attenuated arc. 16. E. punicifolia. Arc with upright extremities. 17. E. hiemalis. Arc with flatened extremities. Bars $=0.5 \mathrm{~mm}$ $(15,16) ; 0.25 \mathrm{~mm}(17)$. 
O uso do padrão de nervação foliar aliado à análise do sistema vascular no pecíolo permitiu a separação da grande maioria dos táxons, exceção feita ao par E. blastantha / E. involucrata. Apesar dessas duas espécies possuírem características reprodutivas e vegetativas muito diferentes (Legrand \& Klein 1969), suas folhas são bastante semelhantes, diferindo apenas na forma de suas bases, na relação comprimento/largura, e na coloração e textura de suas lâminas.

Concordando com as observações de Klucking (1988), Khatijah et al. (1992), Fontenelle et al. (1994) e Costa et al. (1995), os resultados aqui obtidos demonstram que o padrão de nervação foliar e a configuração do sistema vascular do pecíolo são caracteres vegetativos que podem, seguramente, auxiliar na identificação das espécies de Eugenia, indicando que estudos dessa natureza podem e devem ser estendidos a outros grupos, da mesma família.

Agradecimentos - A Lúcia Helena Soares e Silva pela identificação do material. C.M.V. Cardoso e M.G. Sajo agradecem ao apoio do CNPq pelas bolsas concedidas (Bolsa de Mestrado e de Produtividade em Pesquisa, respectivamente).

\section{Referências bibliográficas}

BALHANA, A.P., MACHADO, B.P. \& WESTPHALEN, C.M. 1969. História do Paraná. Grafipar, Curitiba.

COSTA, C.G., MACHADO, R.D. \& FONTENELLE, J.B. 1995. Sistema vascular em folhas de Eugenia L. (Myrtaceae). Bradea 42:345-356.

DU PLESSIS, E. \& VAN WIK, A.E. 1982. The genus Eugenia (Myrtaceae) in southern Africa: taxometrics of foliar organography. South African Journal of Botany 1:147-157.
FABRIS, L.C. \& CESAR, O. 1996. Estudos florísticos em uma mata litorânea no sul do estado do Espírito Santo. Boletim do Museu de Biologia Mello Leitão 5:15-46.

FONTENELLE, J.B., COSTA, C.G. \& MACHADO, R.D. 1994. Foliar anatomy and micromorphology of eleven species of Eugenia L. (Myrtaceae). Botanical Journal of Linnean Society 115:111-133.

HICKEY, L.J. 1974. Classificacion de la arquitetura de las hojas de dicotiledoneas. Boletín de la Sociedad Argentina de Botánica 16:1-26.

HOWARD, R.A. 1979. The petiole. In Anatomy of the dicotyledons (C.R. Metcalfe \& L. Chalk, eds.). Claredon Press, Oxford, v.1, p.88-96.

JOHNSON, C.T. 1980. The leaf anatomy of Leptospermum Forster. Australian Journal of Botany 28:77-194.

KEATING, R.C. 1984. Leaf histology and its contribution to relationships in the Myrtales. Annals of the Missouri Botanical Garden 71:801-823.

KHATIJAH, H.H., CUTLER, D.R. \& MOORE, D.M. 1992. Leaf anatomical studies of Eugenia L. (Myrtaceae) species from Malay Peninsula. Botanical Journal of Linnean Society 110:137-156.

KLUCKING, E.P. 1988. Leaf venation patterns. v.3. J. Cramer, Stuttgart.

KRAUS, J.E. \& ARDUIN, M. 1997. Manual básico de métodos em morfologia vegetal. EDUR, Rio de Janeiro.

LEGRAND, C.D. \& KLEIN, R.M. 1969. Mirtáceas: Eugenia. In Flora Ilustrada Catarinense (R. Reitz, ed.). Herbário Barbosa Rodrigues, Itajaí, p.45-216.

MAACK, R. 1968. Geografia física do Estado do Paraná. J. Olympio, Rio de Janeiro.

MORI, S.A., BOOM, B.M., CARVALINO, A.M. \& SANTOS, T.S. 1983. Ecological importance of Myrtaceae in an eastern Brazilian wet forest. Biotropica 1:68-70.

SOLEREDER, H. 1908. Systematic anatomy of the Dicotyledons. Clarendon Press, Oxford, v.1, p.350-355. 